\section{Three blacks on research council}

\section{Cape Town}

THE South African government has added black representatives to the Scientific Advisory Council (SAC), which advises the cabinet on how to allocate science funding among the various science councils and national facilities. Three of the 13 members of the present council, which met for the first time on 27 August, are black academics.

The SAC does remain, however, safely under the control of the old guard, with the appointment of Chris Garbers to a threeyear term as its head. Garbers served for ten years as president of the Council for Scientific and Industrial Research until he retired about 18 months ago.

The three new black members are A.C. Nkabinde, rector of the University of Zululand; Bob Seretlo, dean of the science faculty at the University of Fort Hare; and, perhaps most significantly, Mamphela Ramphele, a newly appointed vice-principal of the University of Cape Town. Ramphele, a medical doctor, was a former close associate of Steve Biko, the black leader who died while in security police detention in 1977. A relative 'radical', Ramphele is unlikely to always agree with the government's official policies.

Opening the new council, the Minister of National Education, Louis Pienaar, offered some hope that things may improve for the South African science budget, which has been declining in real terms for several years. Warning against the perils of cut-

SUPERCONDUCTORS

\section{Fullerene false alarm}

Tokyo

A GROUP of Japanese researchers has retracted a claim to have developed a superconducting fullerene with a record-breaking critical temperature of $57 \mathrm{~K}$. The result, which was reported around the world (Nature 352, 749; 29 August 1991) and sent researchers scurrying to repeat it, was apparently an artefact.

After announcing the claim, the group at the National Research Institute for Metals was flooded with enquiries from researchers unable to duplicate the results. The team, led by Hisashi Sekine, then tried to repeat the experiment, but without success. Eventually they realized that in the original experiment one of the team had put the fullerene samples in the wrong coil of a superconducting quantum interference detector (SQUID) used to measure magnetic fields.

A paper on the research due to be published next month in the Japanese Journal of Applied Physics has been withdrawn, and in a press release the institute apologizes for the trouble caused to fullerene research. ting funds for science, he said, "If there is one area that should not be hurt through hasty actions, it is our science system." The scientific community is taking these sentiments with a grain of salt, however, since shortly after Pienaar was appointed as minister, South Africa experienced worse-than-usual cuts in budgetary allocations to the research councils (Nature 350, 549; 18 April 1991); those cuts were the first ever in nominal terms, as opposed to real terms.

The SAC's most important function is to advise the cabinet on the distribution of the science 'vote', or budget, among the five statutory councils and the three national facilities - the National Accelerator Centre, the South Africa Astronomical Observatory and the Hartebeesthoek Radio Astronomy Observatory. (The national facilities are part of one of the councils, the

\section{New Delhi}

A LOW-PRICED, deadly pesticide has become the suicide agent of choice in India, alarming doctors and social workers, who say it has made suicide too easy. The pesticide is sold in the form of 3-gram tablets packed in a plastic phial about the size of a pen. Over the last five years, more Indians have taken their lives by consuming this death pill than died in the gas leak from the Union Carbide pesticide plant in Bhopal in 1984.

Because it is efficient, easy to apply and very cheap, aluminium phosphide (ALP) has been the pesticide of choice for fumigating stored grains in India. Although it is meant for use in government silos exclusively by government officials, ALP has entered the retail market and emerged as the most common suicide agent. It has supplanted all other types of poisons used for suicides in most Indian states, and central forensic science laboratory sources say it is also increasingly being implicated in homicides.

The toxic effects of ALP are due to the deadly phosphine gas liberated when it comes in contact with moisture in stored grains. Two tablets of ALP can protect one ton of wheat from pests. When consumed by humans, it reacts with hydrochloric acid or water in the stomach, releasing the poison gas. A single tablet gives off one gram of phosphine, ten times the lethal dose. Death follows in two hours and ALP has no antidote - attributes that have raised its popularity as a suicide agent even among illiterate villagers.

Doctors and social workers have demanded tighter control on its use and have even called for a ban on production of ALP. The government admitted in the

Foundation for Research Development, but are run on separately earmarked funds.) The SAC's recommendations are not made public, so whether budgetary allocations reflect them or overriding decisions by the cabinet is always a matter of conjecture. The proportion of the vote allocated to each council remained roughly constant from 1985 until this year, when cuts varied slightly among the councils.

Pienaar's speech specifically asked the new council to investigate the views of "new and important role players on the political scene" on science policy, and advise the government accordingly. With changed priorities in South Africa, the advisory council may decide to allocate resources differently. The science vote will be increased next year to provide for a new statutory council, the Agricultural Research Council, to be established on 1 April, so the SAC could use the opportunity to reassess the country's scientific priorities.

Michael Cherry

\title{
Death pills from pesticide
}

parliament last week that deaths due to all pesticide poisoning increased from 192 in $1988-89$ to 664 in $1989-90$, but ruled out a complete ban on ALP as it might offset the gains of green revolution. Unofficial figures of pesticide-related deaths are much higher.

Reports of ALP poisoning - unknown before 1980 - have come in from hospitals from several states of India. A single hospital in Rothak in the state of Haryana received 418 cases in a seven-year period, of whom 286 were attempted suicides. According to doctors of the hospital, incidence of ALP poisoning in that state increased from 0.2 per thousand hospital admissions in 1982 to 3 per thousand in 1986 and 5 per thousand in 1987. In fact, every suicide victim brought to Indian hospitals is assumed to have consumed ALP. And no autopsy of such cases is done without a gas mask, after a reported incident where an autopsy surgeon had to be given first aid after being hit by a jet of phosphine from an excised stomach.

Three companies manufacture ALP and the entire production is purchased by the government Under the official guidelines, ALP should be used only by government grain storage facilities, agricultural departments and authorized pest control operators and cannot be sold in retail outlets for individual use. But these guidelines were not sufficient to prevent the entry of the death pills into the retail market through pilferage or deliberate leaks. Admitting that ALP is sold through unauthorized channels, the government last week announced it would be taking stricter measures to plug the leaks and also asks the manufacturers to pack the poison in pilfer-proof packages. K.S. Jayaraman 